International Journal of Engineering \& Technology, $7(4.5)(2018)$ 130-133
International Journal of Engineering \& Technology
SPC
Website: www.sciencepubco.com/index.php/IJET
Research paper

\title{
IoT Based Irrigation System
}

\author{
Rajesh Kumar Yadav ${ }^{1}$, Rishabh $\operatorname{Dev}^{2}$, Tushar Mann $^{3}$, Tarun Verma ${ }^{4}$ \\ ${ }^{1,2,3,4}$ Delhi Technological University, Delhi \\ *Corresponding author E-mail: rkyadav@dtu.ac.in
}

\begin{abstract}
Availability of fresh water is one of the elementary conditions for life on Earth, however, water is a limited resource, which is now under an unprecedented pressure by global population growth, climate change and demand from several economic sectors. In particular, irrigated agriculture is one of the major water-consuming sectors. The aforementioned issues justify the need for a sustainable and rational use of water in irrigated crops.

An IoT based irrigation system helps in supplying adequate amount of water to field and domestic crops in all seasons with minimum human interference. To deliver the required amount of water to the soil, we developed a system which works on the data obtained from the sensor nodes about the surroundings. The approach used helped in increasing the lifespan of the sensor nodes. Since the crop was being provided by adequate amount of water, the quality of crop increased.
\end{abstract}

Keywords: IoT; Irrigation System; lifespan of wireless sensor nodes; Micro-controller.

\section{Introduction}

Micro Irrigation, according to [1] is an artificial supplying of water to the root of plant. Irrigation has been used to assist in the growing of agricultural crops, maintenance of landscapes, and revegetation of disturbed soils in dry areas and during periods of inadequate rainfall. There are many uses of irrigation in crop production such as saving crop from frost and preventing weed growth. The traditional approach used techniques such as making water channel, use of watering cans. In these approaches a lot of water is wasted in the process. Hence, there is a dire need of making an efficient system to irrigate the field.

An intelligent automatic irrigation system can be developed to irrigate the field while optimizing the net use of water.

The irrigation system developed in our approach used performs the following functions:

1) Constant monitoring of field's temperature, moisture and humidity.

2) Assessing from the above parameters whether irrigation of the field is required or not.

3) Irrigating the field accordingly.

4) Discontinue the water supply when the threshold amount is reached.

As only the required amount of water is provided to the crops, the net amount of water used is reduced, hence, we are able to conserve our water resources. Secondly, the quality of the crops is improved as adequate amount of water is supplied consistently. Human interference is minimized as the system works automatically. From a study done by MIT [4], it was observed that irrigation in a field severely effects the rainfall pattern in that area. According to the theory developed by the researchers based on their investigation, when a large area is irrigated, surface air temperature is cooled and surface pressure increased. This reaction was conjectured to reduce rainfall over the irrigated land while generating a clockwise circulation that interacts with the prevailing regional wind [9]. The hardware devices used in this approach have the feature of being in either of two states, sleep or active. Until the threshold value of the sensor nodes is reached, the radio controller module remain remains in sleep mode i.e. there is no transaction of data between the radio module and sensor module, hence conserving the battery used.

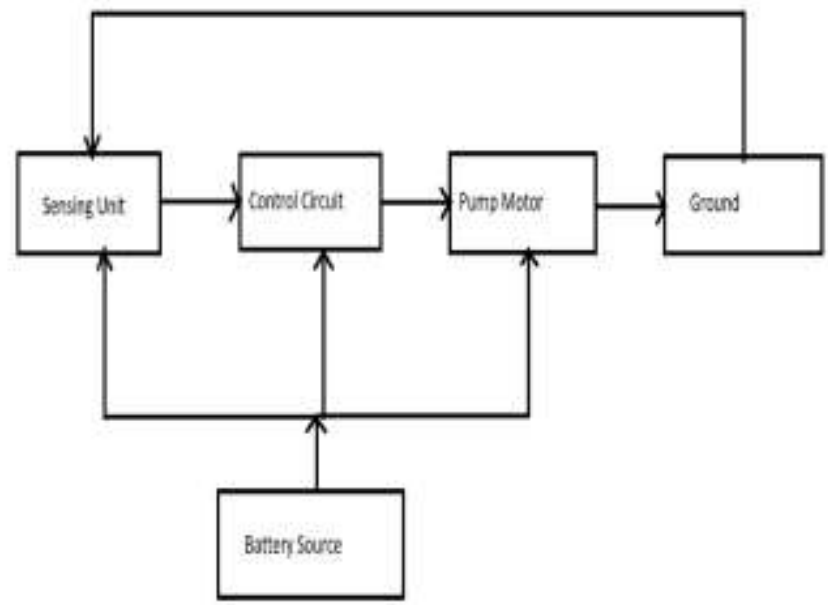

Fig. 1: The system block diagram of automatic irrigation system

Figure 1 represents the circuit used in our approach. Sensing system represents the sensor nodes installed in the field to sense data. The data sensed from this unit is forwarded to the control circuitry which checks whether the values have reached their threshold values or not. If the threshold is reached then the control unit sends a signal to the solenoid valve to release the water in the field. A regulated $24 \mathrm{~V}$ power supply is required to power the system because the microcontroller supplies $3.3 \mathrm{~V}$ only. 


\section{Related Works}

In automatic irrigation system, sensor nodes are used to sense environmental values which are in turn send to a radio controller wirelessly. On the basis of obtained data, the radio module takes decision about irrigating the field. Many schemes are proposed for this purpose and "Cooperative Automatic Irrigation System using Arduino" [2].

The block diagram of the system is shown in fig. 2 consisting of: Arduino Uno: The Arduino Uno is a microcontroller board based on the ATmega328. It has 14 digital input/output pins (of which 6 can be used as PWM outputs), 6 analog inputs, a $16 \mathrm{MHz}$ ceramic resonator, a USB connection, a power jack, an ICSP header, and a reset button.- It contains everything needed to support the microcontroller; simply connect it to a computer with a USB cable or power it with a AC-to-DC adapter or battery to get started[5].

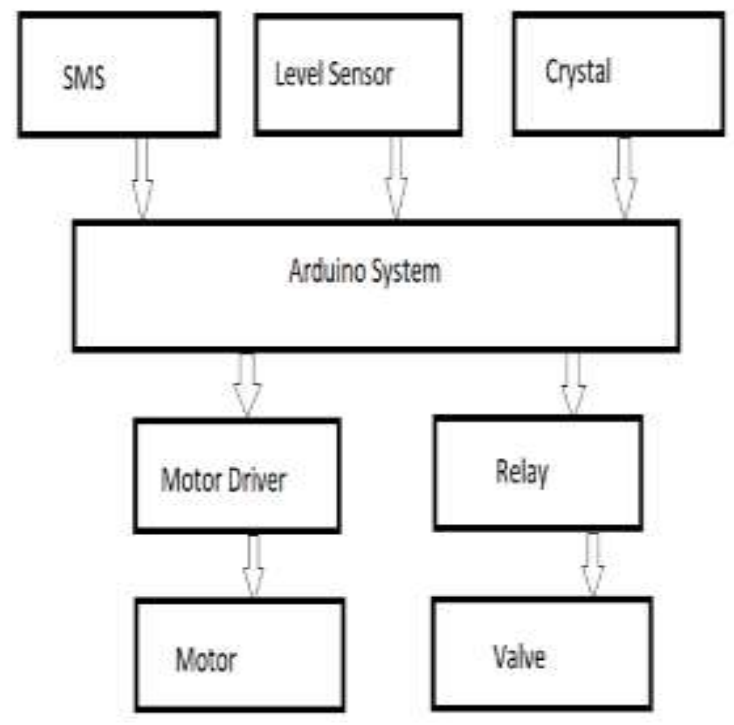

Fig. 2: Block Diagram of the Arduino based system

Relay: is an electrically operated switch and uses an electromagnet to operate a switching mechanism mechanically. A type of relay used here is a high power, required to directly control a solenoid valve. It is used as a means of providing a signal to open the valve for supplying water [6].

The flowchart shown in fig. 3 represents the relation between controller and sensors nodes, the Arduino works as a communication link between them [7]. If the level detected by the sensor is lower than the threshold value, the Arduino sends a message to pumping motor to start the irrigation process. The Arduino always accepts a signal from the sensor. Since, the Arduino hardware always remains active, hence the power consumption is high which results in inefficient battery usage of the system.

The Arduino based automatic irrigation system uses sensor nodes spread across the entire field to sense the environmental condition and according to these values, decision of irrigating the field was taken[8][10]. Since Arduino module is constantly sensing data, its power requirement is high, resulting in non-feasibility of its usage in practical scenarios.

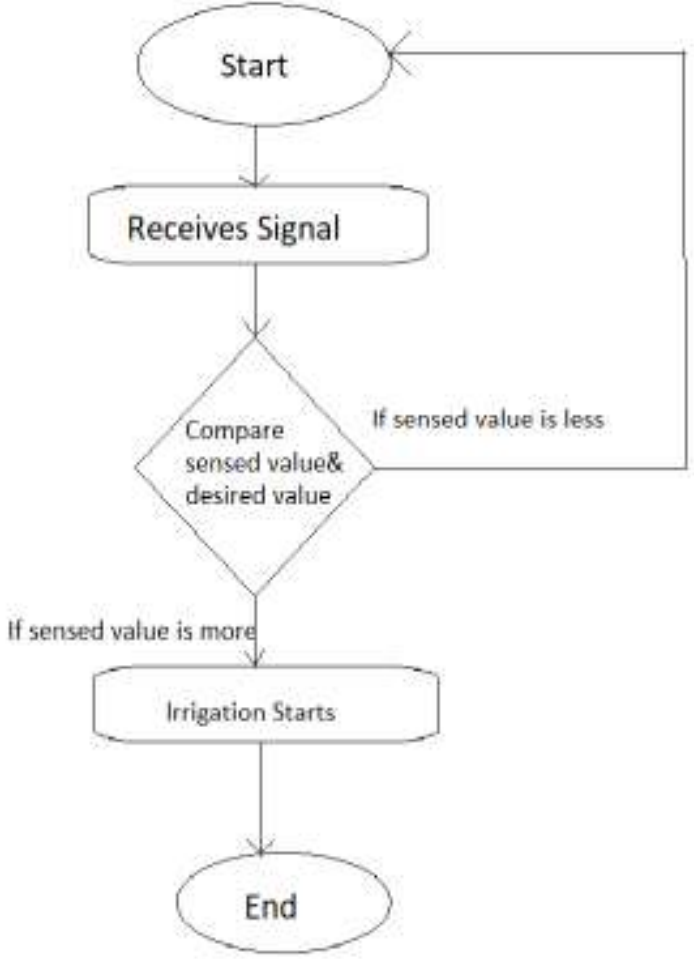

Fig. 3: Flowchart relates soil moisture sensor and the Arduino controller.

\section{Proposed Work}

The idea of the project is to build a IoT based Irrigation system which irrigate the field automatically when the values of soil moisture, humidity and temperature sensed by the sensors are below the critical or threshold limits.

\begin{tabular}{|c|c|c|c|}
\hline$*$ & $*$ & $*$ & $*$ \\
\hline$*$ & $*$ & $*$ & $*$ \\
\hline$*$ & $*$ & $*$ & $*$ \\
\hline
\end{tabular}

Fig. 4: Grid type structure of the farm

The field is divided into grid where each grid consists of a sprinkler which is connected to the water solenoid valve.

The field is divided on the basis of two factors, first, the source of irrigation should be able to irrigate the entire gird and second, the range covered by the sensor.

In our approach, we have tried to save more water by using grid based approach. In other methods on the basis of reading received from sensors if the moisture value lies below the threshold limit the whole field is irrigated but it is not necessary that the whole field needs to be irrigated, there may be some area which needs less irrigation than other parts. Hence, we have used the grid based approach which will irrigate only the part of field which requires irrigation.

The water solenoid valve is connected to the coordinator node which is sensing values of temperature, humidity and soil moisture. The coordinator is sending the sensed data to the PAN coordinator which is connected to the electric motor.

When any grid of the field has the values of soil moisture, humidity and temperature below the threshold ranges, the coordinator generates an interrupt and then sends the sensed data to the PAN coordinator.

As the PAN coordinator receives the data from the coordinator it immediately switch $\mathrm{ON}$ the motor and the water starts flowing through the pipe. The solenoid valve of all the grids will be close except the one grid whose values of soil moisture, humidity and temperature is less than the threshold limits. 
The coordinator sets the DIO pin of the microprocessor to 1 and sends a power of $3.3 \mathrm{~V}$ to the MOSFET whose threshold voltage is $1.5 \mathrm{~V}$. As the DIO pin is set due to which the gate and source get connected which completes the circuit and a voltage of $24 \mathrm{~V}$ is supplied to the water solenoid valve which allows the flow of water through the pipe hence the grids with values of soil moisture, humidity and temperature less then threshold limits are irrigated.

When the values of soil moisture, humidity and temperature reaches the threshold limit, the interrupt is cleared and the coordinator stops sending the data to the PAN coordinator. As the PAN coordinator observes that the interrupt is cleared and no grid need to be irrigated so it switches OFF the electric motor and no more water is supplied. Since the values sensed are between the threshold limits so the coordinator of the grid will clear its DIO pin which will break the circuit since gate and drain are disconnect. So, no power will reach to water solenoid value due to which valve will close and no more water can each that part of field.

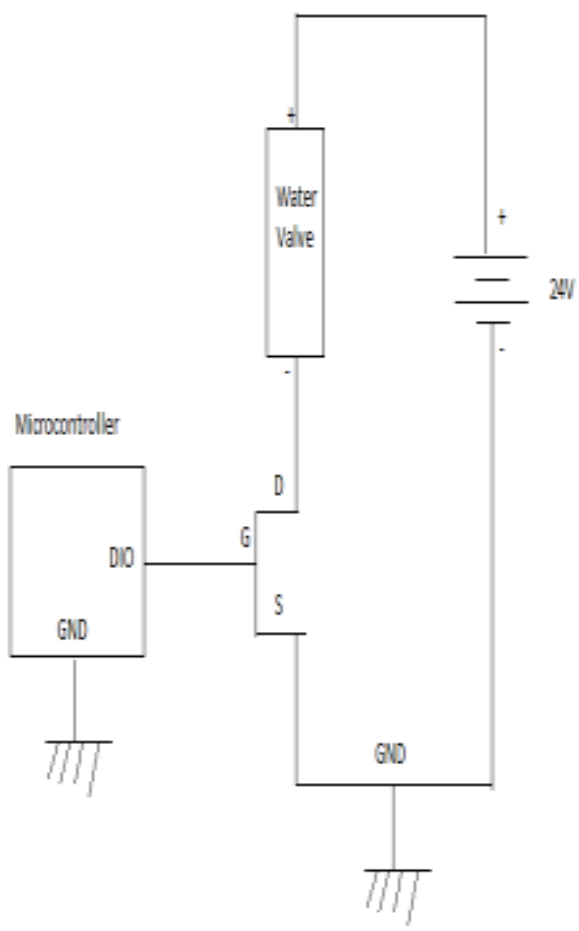

Fig. 5: Circuit Diagram of the System

The circuit consists of the following

1. Microcontroller which contains DIO and ground pins

2. Water solenoid valve

3. 24V DC

4. MOSFET

Problems which could occur-

1. Water logging- There could be possibility that the water have been logged around some sensor so the sensor will always tell the false value.

2. False conditions detected by sensor- There could be possibility that due to some fire in the nearby region the sensor will sense the false value of temperature and humidity and due to which our system can misbehave.

\section{Result and Analysis}

Fig.6 represents the data sensed by the nodes. Three types of data are sensed: temperature, humidity and light. These sensed data is forwarded to the radio module which in turn passes it to the serv- er. The server then takes the appropriate decision and forwards it over to the radio controller.

The radio module remains in sleep mode until the threshold value is sensed and our table shows data only when the module is in active mode. This helps in conserving energy of the module and hence increasing its lifespan.

Since, the system exactly knows which part of the field need to be irrigated and hence it will open only that water solenoid valve whose sensor senses the data outside the critical limits and hence we will be able to save large percentage of water which is wasted during the process of irrigation.

\begin{tabular}{|c|c|c|}
\hline \multicolumn{3}{|c|}{ All Data } \\
\hline Node ID & Soil Moisture & e Temp \\
\hline 2048 & 80.0 & 230 \\
\hline 2048 & 81.0 & 230 \\
\hline $20 A B$ & 81.0 & 230 \\
\hline $20 A B$ & 79.0 & 230 \\
\hline $20 A B$ & 76.0 & 230 \\
\hline 2048 & 78.0 & 230 \\
\hline $20 A B$ & 77.0 & 230 \\
\hline $20 A B$ & 720 & 230 \\
\hline $20 A B$ & 70,0 & 230 \\
\hline 2048 & 69.0 & 230 \\
\hline $20 A B$ & 73.0 & 230 \\
\hline 2048 & 76.0 & 230 \\
\hline $20 A B$ & 75.0 & 23.0 \\
\hline $20 A B$ & 740 & 230 \\
\hline $20 A B$ & 80.0 & 230 \\
\hline $20 A 8$ & 80.0 & 23.0 \\
\hline $20 A B$ & 82.0 & 230 \\
\hline
\end{tabular}

Fig. 6: Interface showing sensed data

Our system is also connected to the weather API with which we can cross check if the value sent by the sensor is correct or not. If the sensor is continuously sensing the false information, then we could easily figure out that the sensor has malfunctioned. This technique will help us to deal with the problems such as water logging problem and false values detected by sensor problem.

The farmer present on remote location will be notified about which part of the field is being irrigated and physical properties of the particular grid such as soil moisture of each gird.

\section{Conclusion}

In this paper, we have proposed a method of irrigating the field which not only works without human interference but is also water and energy efficient. We started by reviewing traditional irrigation methods and some new techniques such as Arduino based

Irrigation System that is being used at present and the disadvantages of these methods. Hence, we proposed our method which takes parameter such as soil moisture and temperature as input through sensors and on basis of that irrigate the field which is divided into grids to save the water used in irrigation. The other better aspect of this approach is the use of sleep and active mode. Whenever the sensed values are below threshold limits, the radio module goes into sleep mode hence, avoiding unnecessary wastage of battery and increasing the lifespan of the system. These two aspects of proposed method try to cover the shortcoming of the methods previously used and make process of irrigation more efficient. 


\section{References}

[1] P., \& P. R. (2016). Design and Implementation of Automatic Plant Watering System. International Journal of Advanced Engineering and Global Technology.

[2] D., P. S., R. A., \& V. T. (2017). Microcontroller Based Automatic Plant Irrigation System. International Research Journal of Engineering and Technology.

[3] Bakker, J. (1995). Greenhouse climate control: an integrated approach. Wageningen Academic Pub.

[4] K. K., V. Z., S. S., S. D., \& K. J. (2016). Sensor based Automated Irrigation System with IOT. International Journal of Computer Science and Information Technologies.

[5] M. D., \& S. O. (2011). A wireless application of drip irrigation automation. Scientific Research and Essays,(pp. 1573-1582).

[6] N. M., R. P., S. K., \& T. S. (2015). Automatic irrigation system on sensing soil. International Journal of Innovative Research in Electrical, Electronics, Instrumentation and Control Engineering.

[7] P. D., \& M. S. (2014). GSM based Automatic Irrigation Control System for Efficient. IOSR Journal of Mechanical and Civil Engineering (IOSR-JMCE), (pp. 49-55).

[8] S. H., R. S., S. K., U. V., \& T.Viveknath. (2014). Solar Powered Smart Irrigation System. Advance in Electronic and Electric Engineering., (pp. 341-346).

[9] S. P., \& D. B. (2014). Microcontroller Based Automated Irrigation System. The International Journal Of Engineering And Science, (pp. 06-09).

[10] S. R., \& A. P. (2014). Microcontroller based Controlled Irrigation System for Plantation. International MultiConference of Engineers and Computer Scientists. 